\title{
ОСОБЕННОСТИ ПРОФЕССИОНАЛЬНОГО САМООПРЕДЕЛЕНИЯ ПОДРОСТКОВ С ОГРАНИЧЕННЫМИ ВОЗМОЖНОСТЯМИ ЗДОРОВЬЯ
}

\section{FEATURES OF PROFESSIONAL SELF-DETERMINATION OF ADOLESCENTS WITH DISABILITIES}

N. Mazurova

E. Sabirova

Summary: This article presents the results of a study of the motives for choosing a profession by adolescents with disabilities. The sample consisted of 60 students in grades 9-10: 30 normally developing adolescents and 30 hearing impaired adolescents with normal intelligence. The authors analyzed the type of professional orientation, personality traits associated with the choice of a profession, the characteristics of the motivational-need-related sphere and the motives for choosing a profession. It was shown that the professional orientation of modern adolescents with hearing impairments is not associated with disabilities, but is determined by such values as "prestige», «money», "career growth». The needs for recognition and self-actualization of these adolescents are not being met.

Keywords: professional choice, self-determination, adolescents with disabilities.

\author{
Мазурова Надежда Владимировна \\ Д.nсх.н., профессор, Российский государственный \\ гуманитарный университет \\ rsuh@rsuh.ru \\ Сабирова Эльвина Ильгизовна \\ учитель, Институт среднего профессионального \\ образования им. К.Д. Ушинского, Москва \\ elvina.sabirova2015@yandex.ru
}

Аннотация: Представлены результаты исследования мотивов выбора профессии подростками с ограниченными возможностями здоровья. Выборку составили 60 учеников 9-10 классов: 30 нормативно развивающихся подростков и 30 слабослышащих с нормальным интеллектом. Анализировались тип профессиональной направленности, наиболее яркие качества личности, связанные с выбором профессии, особенности мотивационно-потребностной сферы и мотивы выбора профессии. Показано, что профессиональная направленность современных подростков с нарушениями слуха не связана с ограниченными возможностями здоровья, а определяется такими ценностями как «престиж», «деньги», «карьерный рост». В зоне неудовлетворенности этих подростков находятся потребности в признании и самоактуализации.

Ключевые слова: профессиональный выбор, самоопределение, подростки с ограниченными возможностями здоровья.

Значительной проблемой таких детей является психологическая неподготовленность к жизни в имеющейся системе социальных отношений $[2,3]$. Прежде всего, это обусловлено типом органической патологии, характером и степенью ее выраженности, особенностями проявления заболевания, спецификой изменений пораженных органов и систем, а также характером вторичных отклонений в развитии $[7,8]$. Диапазон различий в развитии детей и подростков с ОВЗ чрезвычайно велик. В зависимости от вариационных особенностей патологии некоторые дефекты могут практически полностью преодолеваться при правильном процессе обучения и воспитания ребенка, другие иметь латентный характер, а третьи только отчасти компенсироваться [5, 7].

Основной детерминантой успешного выбора профессии является профессиональный интерес или профессиональная направленность. Понять реальное психологическое содержание выбора профессии можно через анализ мотивов, лежащих в основе субъективного отношения человека [4].

Единого взгляда на то, как происходит выбор про- 
фессии у подростков с ОВ3, какие факторы влияют на этот процесс, по-прежнему нет. Их профессиональная ориентация и профессиональная адаптация требует разработки специальных методов диагностики профессиональных интересов и склонностей с учетом состояния здоровья. К сожалению, на федеральном уровне отсутствует диагностический инструментарий, необходимый для профориентации данной группы детей и подростков.

На современном этапе развития общества, с формированием демократических принципов образования, появлением инклюзивного типа образовательных учреждений возникла необходимость учета индивидуальных способностей и возможностей учащихся при проведении профориентационной работы. Для оказания такой квалифицированной помощи подросткам с ОВ3 необходимо владеть информацией о состоянии их мотивационно-потребностной сферы относительно выбора профессии.

Нами было предпринято исследование с целью изучения мотивов выбора профессии подростками с ограниченными возможностями здоровья, в частности с нарушением слуха.

Исследование проводилось на базе двух образовательных учреждений: предуниверсарий МГПУ г. Москвы и ОГКОУ «Школа-интернат для обучающихся с ОВ3 18» г. Ульяновск. Было сформировано две группы респондентов: 30 подростков группы «норма» (20 девочек, 10 маль- чиков) и 30 слабослышащих подростков (24 девочки и 6 мальчиков). Все - ученики 9-10 классов. Для проведения эмпирической части исследования мы использовали следующие методики: тест Дж. Холланда для выявления типа профессиональной направленности; методику «Семь качеств личности» Р. Кеттелла в модификации А.Г. Грецова; методику «Пирамида» Е.Л Бережсковской и А.М Прихожан; методику «Мотивы выбора профессии» Р.В. Овчаровой.

\section{Ход и результаты исслеАования}

По данным методики изучения профессиональной направленности Дж. Холонда подростки с ограниченными возможностями здоровья склоны к реалистичному (47\%), интеллектуальному (20\%), конвенциональному (13\%), предприимчивому (13\%), социальному (7\%) типам профессиональной направленности. Никто из подростков с ОВ3 не выбрал артистический тип. Таким образом, большинство подростков с ОВЗ предпочитают работать с вещами, а не с людьми, заниматься конкретными объектами и их использованием, ориентированы на четко структурированную деятельность.

Их сверстники с нормальным слухом склонны к артистическому (53\%), социальному (20\%), предприимчивому (13\%), реалистичному 7\% и интеллектуальному 7\% типам профессиональной направленности. То есть, при выборе профессии они в большей степени опираются на интерес, эмоции и общение с людьми (диаграмма 1).

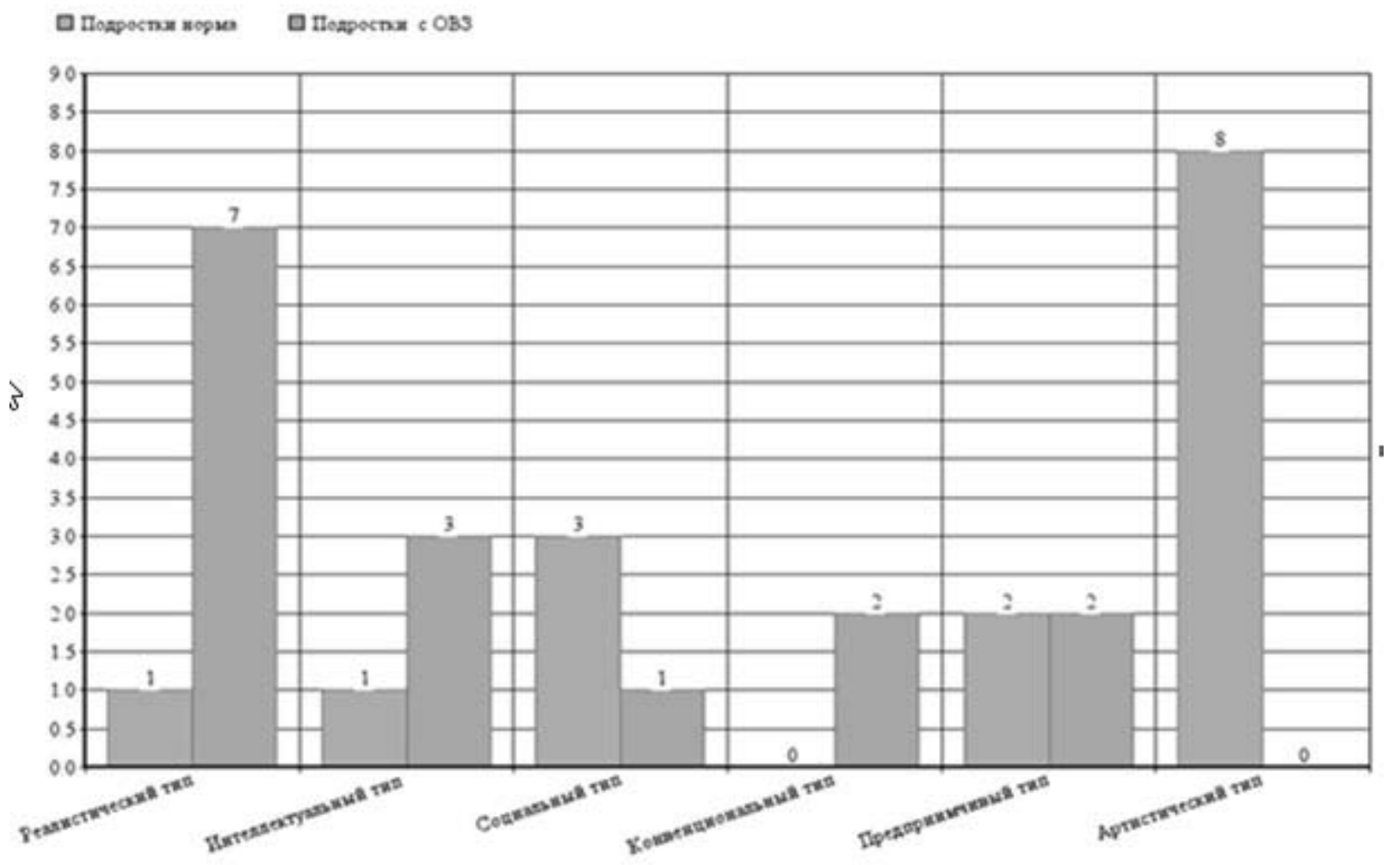

Диаграмма 1. Результаты исследования по методике Холланда 
Была проведена проверка различий между группами с использованием U-критерия Манна - Уитни. Результаты находятся вне зоны значимости: UЭмп = 17. То есть, профессиональная направленность подростков с ОВ3 не связана с их ограниченными возможностями здоровья, а скорее определяется их личными качествами.

По результатам методики «Семь качеств личности» Р. Кеттела подростки с ограниченными возможностями здоровья характеризуются как замкнутые (26\%), тревожные (26\%), эмоционально неустойчивые (20\%), робкие (20\%). Они испытывают трудности в принятии решения и часто полагаются на мнение родителей, бурно реагируют на препятствия. Слабо развиты такие качества как: склонность к доминированию и подозрительность. У нормально развивающихся подростков ярко выражены такие качества как: доминирование (53\%), подозрительность (46\%), эмоциональная устойчивость (40\%), общительность (33\%). Они характеризуются постоянством интересов и могут адекватно реагировать на неожиданные повороты событий (диаграмма 2).

Расчет U-критерия Манна Уитни: UЭмп = 6, между группами подростков в норме и подростков с ОВЗ действительно существуют значимые различия в качествах личности.

По результатам методики «Пирамида» Е.Л. Бережсковской и А.М. Прихожан у подростков с ограниченны- ми возможностями здоровья в зоне удовлетворенности находятся физиологические потребности, потребность в безопасности и принятии. В зоне неудовлетворенности находятся потребности в признании и самоактуализации. Им свойственны следующие варианты ответов: «для меня важно, чтобы окружающие меня принимали, относились ко мне хорошо», «мне важно чувствовать, что родители не сердиться на меня, что у нас все в порядке» и др. Подростки зависимы от внешних факторов, их деятельность направлена на получение одобрения родителей и других взрослых.

Расчет U-критерия Манна Уитни: UЭмп = 6, между группами подростков в норме и подростков с ОВ3 действительно существуют значимые различия в качествах личности.

По результатам методики «Пирамида» Е.Л. Бережсковской и А.М. Прихожан у подростков с ограниченными возможностями здоровья в зоне удовлетворенности находятся физиологические потребности, потребность в безопасности и принятии. В зоне неудовлетворенности находятся потребности в признании и самоактуализации. Им свойственны следующие варианты ответов: «для меня важно, чтобы окружающие меня принимали, относились ко мне хорошо», «мне важно чувствовать, что родители не сердиться на меня, что у нас все в порядке» и др. Подростки зависимы от внешних факторов, их деятельность направлена на получение одобрения родите-

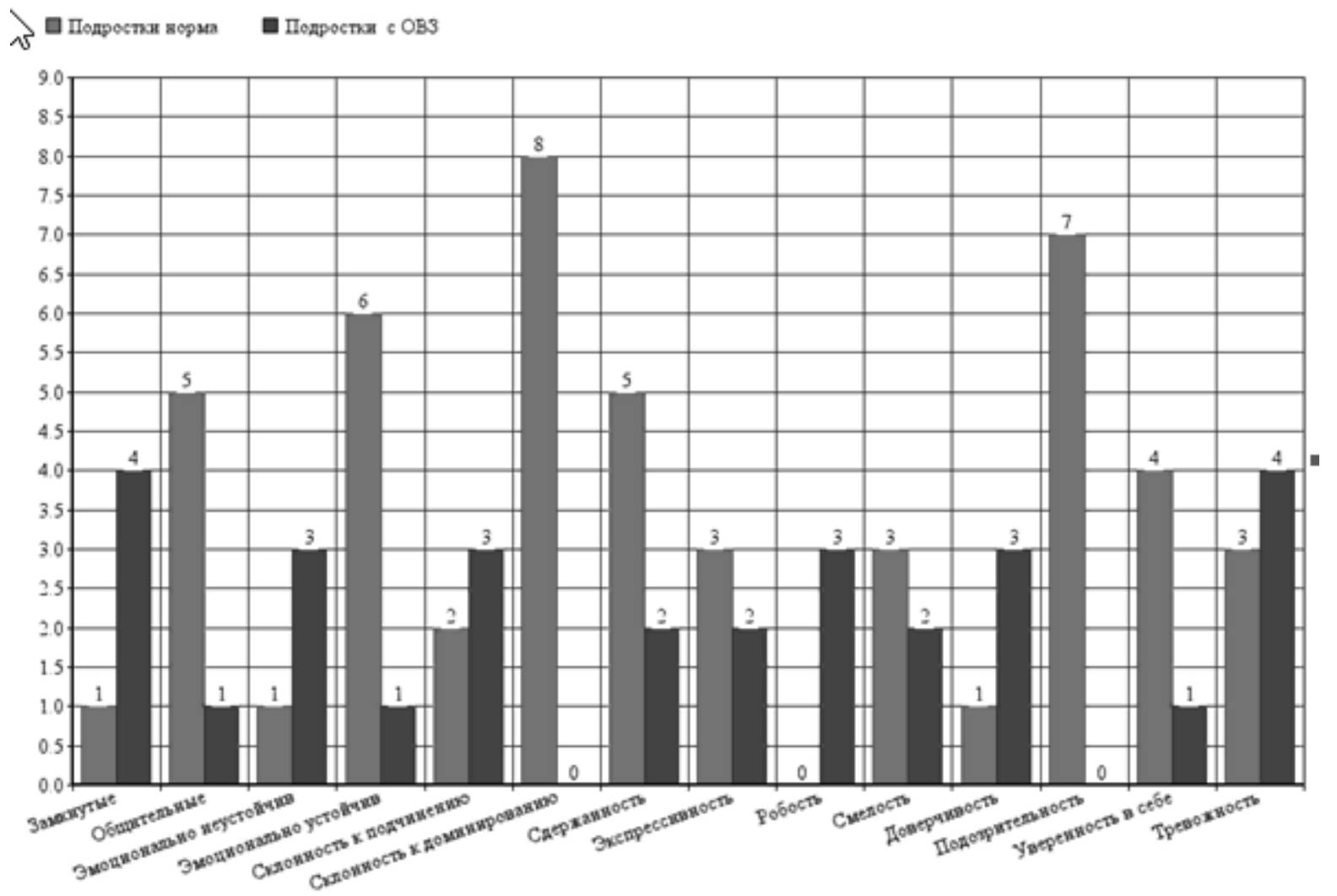

Диаграмма 2. Результаты исследования по методике «Семь качеств личности» 
лей и других взрослых.

В группе нормально слышащих подростков в зоне удовлетворенности находятся физиологические потребности и потребность в безопасности. В зоне неудовлетворенности находятся потребности в принятии (любви), признании и самоактуализации. Для них свойственны следующие варианты ответов: «самое интересное в жиз- ни - создавать что-то новое, чего раньше не было», «главное в моей жизни - это мои творческие увлечения», «у меня есть любимое дело, с ним связано мое будущее». То есть, потребность в самоактуализации исходит от самого подростка, а не от внешних факторов.

С помощью U-критерия Манна Уитни была проведена проверка различий между группами подростков. Ана-

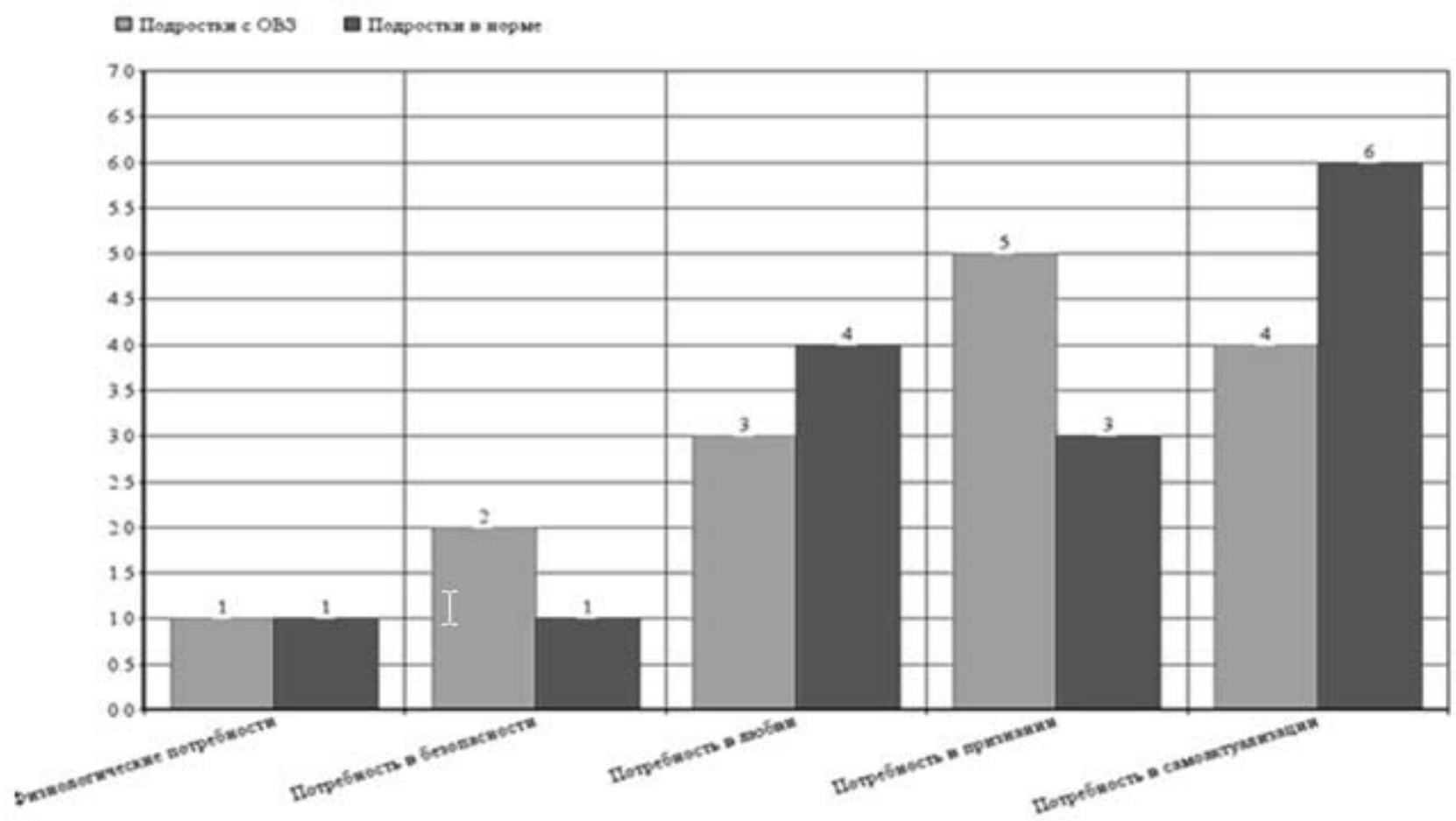

Диаграмма 3. Результаты исследования по методике «Пирамида»

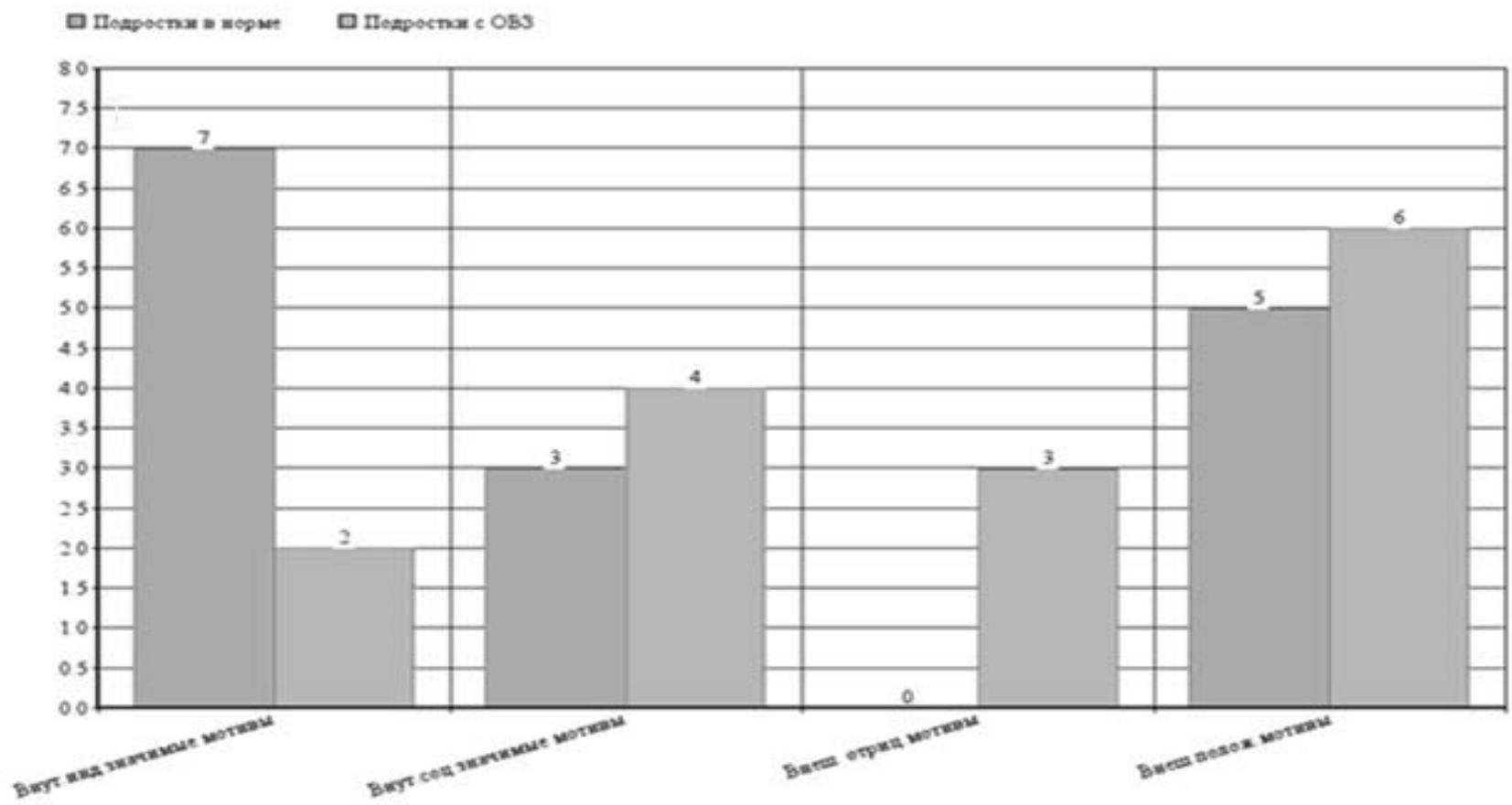

Диаграмма 4. Результаты исследования по методике «Мотивы выбора профессии» 
лиз результатов показал, что между подростками с ОВ3 и подростками в норме значимых различий нет.

Исследование мотива выбора профессии с использованием методики Р.В. Овчаровой позволило получить следующие результаты (диаграмма 4).

Подростки с ОВ3 чаще опираются на внешне положительные мотивы (40\%), их привлекает престиж профессии и уровень зарплаты. Еще 20\% выборов - это внешне отрицательные мотивы, 13\% - индивидуально значимые мотивы. Многие ребята опасаются, что из-за неправильно выбранной профессии их будут критиковать или осуждать. Наиболее предпочтительными ценностями, на которые опираются подростки с ОВ3, являются «деньги», «карьерный рост», «престижность», что свидетельствует о доминировании прагматической ориентации. Более половины подростков с ОВЗ точно не смогли определить свои профессиональные интересы, они не готовы к самостоятельному выбору профессии и нуждаются в помощи по определению своих профессиональных склонностей.

Нормально слышащие подростки при выборе профессии опираются на индивидуально значимые мотивы (47\%), внешне положительные мотивы (33\%), внутренние социально значимые мотивы (20\%). Важными ценностями для них при выборе профессии являются «интерес к профессии», «творчество», «стабильность». Их привлекает творческая реализация в труде, духовное и физическое развитие, общественная значимость профессии.

\section{Выводы}

По результатам проведенного исследования мы можем сформулировать выводы относительно профессио- нального самоопределения подростков с ограниченными возможностями здоровья.

Большинство подростков с ОВЗ склонны к реалистичному типу профессиональной направленности. Это несоциальный, стабильный, ориентированный на настоящее, занимающийся практическим использованием объектов тип. Подростки характеризуют себя как замкнутые, тревожные, доверчивые, робкие, склонные к подчинению, эмоционально неустойчивые. Для них не характерны доминирование и общительность. В мотивационно-потребностной сфере подростков в зоне удовлетворенности находятся физиологические потребности, потребность в безопасности и потребность В принятии. В зоне неудовлетворённости находятся потребность в признании и самоактуализации. Преобладающими мотивами выбора профессии являются внешне положительные и внутренне социально значимые мотивы. Наиболее предпочтительными ценностями, на которые ориентируются подростки, являются: «престижность», «деньги», «карьерный рост». Основная масса подростков с ОВ3 не определилась с ведущими профессиональными интересами.

Таким образом, выбор профессии подростками с ограниченными возможностями здоровья определяется ценностными ориентирами родителей. Сами выпускники школ не владеют информацией о профессиях, а также имеют искаженные представления о своих возможностях. Профориентацию подростков с ОВЗ необходимо осуществлять комплексно, с участием специалистов. Для полноценной социализации выпускников с ограниченными возможностями здоровья нужна единая программа личностной психологической диагностики и профориентирования с учетом индивидуальных возможностей подростков и состояния их здоровья.

\section{ЛИТЕРАТУРА}

1. Абрамова, Г.С. Возрастная психология: Учебное пособие для студ. вузов. - М.: Издательский центр «Академия», 2014. - 672 с.

2. Андросова Г.Л. Курс «Социально-бытовая ориентировка» как педагогическое средство социализации подростка с нарушением интеллекта. М.: Педагогика, 2003.

3. Бгажнокова И.М. Воспитание и обучение детей и подростков с тяжелыми и множественными нарушениями развития. М.: Педагогика, 2007. 247 с.

4. Климов Е.А. Психология профессионального самоопределения: учебное пособие для студентов высших учебных заведений. - М.: Издательский центр «Академия», 2010. - 304 с.

5. Лебединский В.В. Нарушение психического развития. М.: Педагогика, 2004. - 306 с.

6. Мазурова Н.В., Исаева 0.В. Взаимосвязь ценностно-смысловых установок родителей и особенности детско-родительского взаимодействия в семье // Ученые записки РГСУ. - 2018. - Т. 17. - №2. С. 39-50.

7. Основы специальной психологии / Под ред. Л.В. Кузнецовой. - М., Издательский центр «Академия», 2010. - 480 c.

8. Психолого-педагогическое сопровождение семьи ребенка с ограниченными возможностями здоровья. Учебник для студентов учреждений высшего профессионального образования / Под ред. В.В. Ткачевой. - М: Издательский центр «Академия», 2014. - 272 с.

с Мазурова Надежда Владимировна (rsuh@rsuh.ru), Сабирова Эльвина Ильгизовна (elvina.sabirova2015@yandex.ru), Журнал «Современная наука: актуальные проблемы теории и практики» 